\title{
Introduction: The Dynamics of Happiness and the Dynamics of Happiness Research
}

\author{
Hilke Brockmann • Jan Delhey
}

Accepted: 10 November 2009/Published online: 18 December 2009

(C) Springer Science+Business Media B.V. 2009

Happiness research is mushrooming. National rankings of the happiest populations and insights into which factors boost happiness are in demand as much from a growing international scientific community as from policy makers and the general public. This is probably no accident in post-modern times. The concept is down-to-earth, innocent, and non-ideological, but promising and in everyone's vocabulary rut. Happiness may refer to either shortterm emotional states, or long-term cognitive evaluations (Ryff 1989; Veenhoven 1996a, b; Kahneman 2000). Yet, it always rests on the individual capacity to distinguish between good and bad environmental stimuli, and it triggers behavioral responses.

In the academic context, happiness has a long philosophical tradition, a biological core, a close match with economics, psychological standing, sociological significance, and political implications; this is way more than other concepts can offer. Thus, it is no coincidence that researchers from all of these areas contribute to the "new science of happiness" (Layard 2005), helping step by step to unlock the mysteries of "psychological wealth" (Diener and Biswas-Diener 2008). Frey (2008) even attests that happiness research has revolutionary potential. This is certainly true for economics, if satisfaction ratings become a gold standard for measuring individual utility. In a broader sense, this new science promotes the subjective measurements of well-being, and consequently shifts the power from the expert (i.e. the scientist) to the layperson. The normative implications are far reaching. In the tradition of Bentham, the "new utilitarianism" advocates the maximization of individual happiness as the guiding principle for public policy (Veenhoven 2004). Just imagine: happy patients in public health care, happy pupils in public schools, and happy unemployed labor in state-subsidized work schemes.

Yet, such ambitious and happy outlooks need solid groundwork in research. The last two decades have increased knowledge about happiness immensely. To start with, we know today that survey methods are a valid and reliable source for measuring "life-

H. Brockmann $(\bowtie) \cdot$ J. Delhey $(\bowtie)$

Jacobs University Bremen, School of Humanities and Social Sciences, Campus Ring 1, 28759 Bremen, Germany

e-mail: h.brockmann@jacobs-university.de

J. Delhey

e-mail: j.delhey@jacobs-university.de 
happiness" (Veenhoven 1996a, b) — the subjective enjoyment of life as a whole. All contributions to this volume rest on survey data and focus on this understanding of happiness as life satisfaction.

Also, a number of robust factors promoting happiness have been identified on both an individual and societal level. Genetic dispositions, personality traits, health conditions, social relations, to some extent money and material living conditions, religion, and activity increase individual happiness. At the societal level, affluence, democracy, rule of law, (gender) equality, low unemployment, and social capital (trust in particular), lift the subjective well-being of entire countries, positioning Scandinavian countries at the top of the global well-being hierarchy (Inglehart et al. 2008).

Furthermore, many insights have been gained as to how these internal and external conditions translate into subjective well-being, filtered and moderated by rising aspirations (the hedonic treat mill), social comparisons with other people (close or distant, e.g. keeping up with the Johnsons), and values and life priorities. For example, it is known that materialistic people derive less happiness from a given income than non-materialistic people.

What remains to be done? One of the under-explored questions, the authors of this special issue claim, asks about the dynamics of well-being. How does happiness change over time in individuals and in societies, if at all? Longitudinal studies have shown that increasing one of the above mentioned determinants does not necessarily raise happiness. This holds especially for income gains and improvements in material living conditions, known as the 'Easterlin-Paradox' (Easterlin 1974).

In line with personality studies (Diener and Lucas 1999), these findings paved the ground for theoretical models that emphasize stability. Genetically determined personality traits and/or adaptation, resulting from social comparisons or rising aspirations, fix happiness at individual set-points. Even if life circumstances objectively improve or worsen, people's subjective well-being will bounce back to the personal set-point after a short period of time. This stability paradigm comes in different theoretical flavors (see the contribution by Headey in this volume). However, it is challenged by recent studies.

Longitudinal data mirroring individual life trajectories reveals that marriages (Zimmermann and Easterlin 2006), children (Kohler et al. 2005), and unemployment (Clark et al. 2001) alter SWB levels persistently. Country-level researchers claim that SWB goes in tandem with economic progress, although the gains in happiness are not great (Hagerty and Veenhoven 2003). With five waves of the World Values Study now available, Inglehart and colleagues show that SWB has increased in the majority of countries, and remained stagnant in only a few (Inglehart et al. 2008). Although a systematic overview of deviations from the set-point paradigm and a discussion of their theoretical implications are currently lacking, there is cumulative evidence that something is wrong with the set-point paradigm.

Moreover, the fixation on levels of happiness in contemporary research may also account for the oversight of compositional changes which could determine both, fixed and altering levels of SWB. For China, Brockmann et al. (2009) have demonstrated that the enourmous economic progress has hardly changed Chinese sense of life satisfaction, whereas their "recipes of happiness" did change dramatically: Financial satisfaction was elevated from a moderate source of life happiness to the single most important source, which perfectly mirrors the marketization and commercialization of Chinese society. Generally, transition experiences could provide a good testing ground for new "recipes of happiness". Abrupt and far-reaching social changes, such as the economic transformation from communism to capitalism, affect entire populations lastingly and collectively. Individual life course transitions, like labor market entries and entries into parental life, are 
other examples of alterations of opportunity structures. Several authors of this volume claim that societal transformations and individual transitions translate into a new composition of happiness, and they do so in a highly predictable manner. However, until now the possibility of changing sources of happiness was not really an issue within the set-point paradigm.

To systematically learn about the dynamics of happiness, data has to comprehend temporal and spatial variation. Yet, most happiness studies have focused on short time intervals, and on Western countries. This limited cutout of the varieties of happiness may bias the findings and conclusions (Inglehart et al. 2008). Authors of this volume face up to the criticisms; their studies draw on both longitudinal and global data. They also consider the varieties of determinants of happiness on the individual level, as well as on the country level, and introduce new theoretical approaches that better integrate stability and change in happiness.

Bruce Headey's paper traces the historical rise and the beginning descent of the setpoint paradigm in happiness research. He undertakes the first systematic empirical study with the longest available time series on life satisfaction, the German Socio-Economic Panel Survey, to quantify the magnitude of permanent deviations from an individual setpoint. With up to $30 \%$ of the panel members having experienced large and persistent changes in their set-points, he adds heavy weight to his claim for a new dynamic theory that embraces both stability and change in SWB. Headey also demonstrates that life priorities are key for shifting set-points lastingly by engaging in non-zero-sum games, rather than in zero-sum games.

The following papers share a developing new theory of happiness. Hilke Brockmann's paper adds ill-being as an inseparable downside of happiness, and combines various timing processes (e.g. "social clocks") to a new, dynamic model. Her multi-level analysis of SWB across the life-course is also based on GSOEP data, and reveals significant age, period, and cohort effects. Mid-life "depression" is explained by a social investment dilemma. Committed to long-term love and labor investments, the middle-aged in affluent societies, although wealthy, are trapped between a high risk of disappointment when former investments turn sour, and a high chance that new investments will pay off in a pro-longed future. This dilemma turns them into "frustrated achievers".

Christian Welzel and Ronald Inglehart broaden the perspective and draw an evolutionary bow from agency and well-being to human development. They develop a sequence model in which the widening life opportunities that emerge with post-industrial knowledge societies nurture an increased emphasis on emancipative values, which in turn results in an increasing importance of agency for individual well-being. As agency becomes more important for well-being, the level of well-being itself is about to rise. Since agency is a 'non-rival good', investing in agency is an investment into a non-zero-sum game that, according to Headey, should yield higher satisfaction rates. This evolutionary model is confirmed by global data from the World Value Surveys, and tested against the potentially confounding influence of Western cultural traditions. Since the model holds against this control, the authors interpret their agency-focused model as a general model of human development.

Resonating with the findings of Welzel and Inglehart, Jan Delhey takes the composition of happiness to an acid test. Is SWB in affluent post-industrial countries more determined by post-material concerns than by materialistic concerns, as Inglehart's theory of value change predicts? Consequently, this paper is not interested in cross-national differences in happiness levels, but in what makes people happy. The most recent World Value Survey data from 48 countries, covering the entire range of socio-economic development, provides 
convincing evidence that "happiness recipes" change when we move from poor to rich societies. This change is mainly driven by a devaluation of material concerns-financial satisfaction is less important for life satisfaction under the condition of affluence. Likewise, post-materialistic concerns, such as personal autonomy and job creativity, become somewhat more important. Both trends cumulate to a shift towards a more post-materialist "happiness recipe" in rich post-industrial countries.

Wolfgang Jagodzinski pursues a theoretical motif when he asks about differences in SWB between Europe and Asia. Happiness research has produced many empirical findings, but little theoretical explanation. Therefore, he conceptualizes a dynamic multi-level model that inputs aspirations and expectations on the one hand, and resources possessed by individuals and opportunity structures imposed by society on the other. His nested theoretical approach of subjective and objective realities comprehends both the emergence and change of happiness. With data from the European Values Study and the Asia Barometer, he can show that at the individual level, respondents' income, national pride, and religiousness boost happiness similarly in Europe and Asia. However, on the macro-level he finds significant differences. In Europe, national income is the only significant contextual factor of the three tested here, whereas in Asia, political integration (level of national pride) and general religiousness contribute to individual SWB as well.

A dynamic theory of happiness needs to account for spatial, cross-cultural differences, but must also be sensitive to temporal historical trends, argues Ruut Veenhoven in his closing paper. In "Life Is Getting Better", he develops a comprehensive quality of life schema, abstracting from contexts, to systematically distinguish life chances from life results, and outer qualities from inner qualities. His categorical system has a biological equivalent, prompting him to tie happiness to longevity. Measured by happy life years, human history followed a non-linear trajectory from pretty happy hunter and gatherer societies, to a less happy life in agrarian communities, and then back to longer and happier modern lives. Also during the last decades, Veenhoven traces an overall uptrend despite singular negative developments, such as rising depression rates. Hence, the key message is optimistic: life is getting better, which is good news, since happy people do a lot of good things to others.

All in all, the papers in this volume contribute additional layers of understanding of the dynamics of happiness, both of individuals and the aggregated happiness of populations at large. Two major messages emerge from the papers. First, happiness levels are not fixed to the extent claimed by set-point theory and its relatives. Hence, we need a new, more flexible paradigm that can also incorporate the "deviant" findings in a meaningful way. This is a major task, and future research will have to test which ingredients and levels of abstraction a dynamic model of happiness requires. Second, something important may be missed when gazing at SWB levels, such as fundamental changes taking place in the deeper determination structure of happiness. Nine tenths of an iceberg is hidden underwater. It is high time to look not only at the tip of the iceberg, but at the iceberg as a whole.

The collection of papers presented here mainly originated from the conference "Dynamics of Happiness", which took place on July 12th and 13th, 2008, at the Hanse Wissenschaftskolleg in Delmenhorst, Germany. The conference was organized by Hilke Brockmann (Jacobs University), Jan Delhey (Jacobs University), and Uwe Opolka (Hanse Wissenschaftskolleg in Delmenhorst). We are very happy that the Hanse Wissenschaftskolleg has supported this conference so generously. Thank you very much! Two papers originated from a lecture series on happiness studies organized at Jacobs University in 2008. We greatly acknowledge the support of Jacobs University for this lecture series, and its general support for the Happiness Research Group at Jacobs University. 


\section{References}

Brockmann, H., Delhey, J., Welzel, C., \& Yuan, H. (2009). The China puzzle: Falling happiness in a booming country. Journal of Happiness Studies, 10, 387-405.

Clark, A., Georgellis, Y., \& Sanfey, P. (2001). Scarring: The psychological impact of past unemployment. Economica, 68, 221-241.

Diener, E., \& Biswas-Diener, R. (2008). Happiness: Unlocking the mysteries of psychological wealth. Oxford: Wiley-Blackwell.

Diener, E., \& Lucas, R. E. (1999). Personality and subjective well-being. In N. Schwarz \& F. Strack (Eds.), The foundations of hedonic psychology (pp. 213-229). New York: Russell Sage.

Easterlin, R. A. (1974). Does economic growth improve the human lot? Some empirical evidence. In P. A. David \& M. W. Reder (Eds.), Nations and households in economic growth (pp. 89-125). New York, London: Academic Press.

Frey, B. S. (2008). Happiness: A revolution in economics. Cambridge, MA: MIT Press.

Hagerty, M. R., \& Veenhoven, R. (2003). Wealth and happiness revisited-growing national income does go with greater happiness. Social Indicators Research, 64, 1-27.

Inglehart, R., Foa, R., Peterson, C., \& Welzel, C. ((2008)). Development, freedom, rising happiness. A global perspective, 1981-2007. Perspectives on Psychological Science, 3, 264-285.

Kahneman, D. (2000). Experienced utility and objective happiness: A moment-based approach. In D. Kahneman \& A. Tversky (Eds.), Choices, values, and frames (pp. 673-692). Cambridge, UK: Cambridge University Press.

Kohler, H.-P., Behrman, J. R., \& Skytthe, A. (2005). Partner + children = happiness? The effects of partnership and fertility on well-being. Population and Development Review, 31, 407-445.

Layard, P. R. G. (2005). Happiness. Lessons from a new science. London: Penguin Books.

Ryff, C. D. (1989). Happiness is everything, or is it? Explorations on the meaning of psychological wellbeing. Journal of Personality and Social Psychology, 57(6), 1069-1081.

Veenhoven, R. (1996a). Developments in satisfaction-research. Social Indicators Research, 37, 1-46.

Veenhoven, R. (1996b). Happy life expectancy: A comparative measure of quality of life in nations. Social Indicators Research, 39, 1-58.

Veenhoven, R. (2004). Happiness as a public policy aim: The greatest happiness principle. In P. A. Linley \& S. Joseph (Eds.), Positive psychology in practice (pp. 658-678). Hoboken: Wiley.

Zimmermann, A. C., \& Easterlin, R. A. (2006). Happily ever after? Cohabitation, marriage, divorce, and happiness in Germany. Population and Development Review, 32(3), 511. 